\title{
Life table and demographic parameters of the coccinellid predatory species, Hippodamia convergens Guérin-Méneville (Coleoptera: Coccinellidae) when fed on two aphid species
}

\author{
Muhammad Arshad ${ }^{1,2^{*}}$ (D), Muhammad Irfan Ullah ${ }^{1,2}$, Umair Shahid ${ }^{1}$, Muhammad Tahir ${ }^{3}$, Malik Imran Khan ${ }^{1}$, \\ Muhammad Rizwan ${ }^{4}$, Muhammad Abrar ${ }^{1}$ and Muhammad Mubashar Niaz ${ }^{1}$
}

\begin{abstract}
The study aimed to determine the effect of two aphid species; Lipaphis erysimi (Kaltenbach) and Aphis gossypii Glover (Hemiptera: Aphididae) on life table and demographic parameters of Hippodamia convergens Gu'erin-M' eneville (Coleoptera: Coccinellidae). The developmental period of all life stages of $\mathrm{H}$. convergens was shorter when fed on L. erysimi. Net reproductive rate $\left(R_{0}\right)$ was higher (159.85 offspring/individual) on L. erysimi, while it was 87.85 offspring/individual on A. gossypii. Mean generation time (T) was shorter (30.49 d) on L. erysimi than on A. gossypii (45.1 days). Values of the intrinsic rate of increase $(r)$ and finite rate of increase $(\lambda)$ were calculated as 0.166 days $^{-1}$ and 1.181 days $^{-1}$, respectively, on L. erysimi that were higher than on A. gossypii (0.099 days ${ }^{-1}$ and 1.104 days $^{-1}$, respectively). Similarly, the survival rate was also higher when the predator was fed on L. erysimi. Overall, the findings suggest using L. erysimi as a better source of prey than A. gossypii for rearing $H$. convergens.
\end{abstract}

Keywords: Hippodamia convergens, Aphis gossypii, Lipaphis erysimi, Life table parameters

\section{Background}

Coccinellidae is a very heterogeneous group of Coleopteran due to their feeding behavior (Sutherland and Parrella 2009). Coccinellids are very important predators and their food resources depend on prey abundance in the environment where they live (Dixon 2000). They are polyphagous and feed on many economic agricultural insect pests such as mealy bugs, aphids, thrips, scale insects, mites, leafhoppers, and other soft-bodied insects (Khan et al. 2009).

\footnotetext{
* Correspondence: makuaf@gmail.com

'Department of Entomology, University of Sargodha, Sargodha 40100, Pakistan

${ }^{2}$ China-Pakistan Joint Research Centre for Citrus Disease and Insect Pest Management, University of Sargodha, Sargodha 40100, Pakistan Full list of author information is available at the end of the article
}

Life parameters of any biological control agent such as development rate and reproductive parameters depend on various biotic and abiotic factors (Jervis et al. 2005). Among the biotic factors, the quality and abundance of food are very important, influencing directly the growth and development of the predator (Dixon 2000). If the food source is unavailable or few or of poor quality, the developmental period usually increases and the reproductive parameters such as fecundity rate and oviposition decrease (Hodek et al. 2012). Previous investigations have reported the importance of foods to the coccinellids reproduction (Omkar and Srivastra, 2003; Lundgren and Wiedenmann 2004; Berkvens et al. 2008 and Lundgren 2009).

Among the coccinellid beetles, prey food varies as they reproduce and develop optimally, when they fed on 
various aphid species (Omkar and Mishra 2005 and Pervez et al. 2018). Aphids are polyphagous insect pests causing economic losses to various agricultural crops (Aslam et al. 2005). Amin et al. (2017) reported 17 different host plants of Aphis gossypii in Pakistan. According to Jessie et al. (2015), a specialist aphid is more toxic to coccinellid predators than a generalist aphid.

To successfully mass rearing the coccinellids in a biological control program, assessment of their population characteristics, such as growth rate, fecundity, and predation rate is very important (Yu et al. 2013). Further, the provision of adequate and nutritional diet is a major concern in the predation potential and biology of coccinellids (De Clercq et al. 2005).

The main objective of this study was to evaluate the effect of two aphid species; Lipaphis erysimi (Kaltenbach) and Aphis gossypii Glover (Hemiptera: Aphididae) on the life table and demographic parameters of the coccinellid predator, $H$. convergens under laboratory conditions.

\section{Materials and methods}

The experiment was performed in the Entomology Laboratory at China-Pakistan Joint Research Centre, University of Sargodha, Pakistan.

\section{Aphid species}

The parthenium weed, Parthenium hysterophorus L. (family: Asteraceae) and wheat plant, Triticum aestivum, (Family: Poaceae) were grown in plastic containers (10 cm diameter) at $25 \pm 2{ }^{\circ} \mathrm{C}, 65 \pm 5 \% \mathrm{RH}$ and a photoperiod of 14:10 (L:D). Plants were irrigated with tap water, and pot weights were recorded twice each day to maintain the soil water contents which were kept the same for both plant species. The nymphs and adults of L. erysimi from wheat plants and A. gossypii from parthenium weed were collected directly from the field, released on the respective host plants and the cultures were maintained up to the 3rd generation.

\section{Culture of $H$. convergens}

The initial culture of $H$. convergens was initiated by collecting adults from the field and maintained in plastic jars $(20 \mathrm{~cm}$ length and $15 \mathrm{~cm}$ diameter) with an abundant supply of aphid species. The culture was maintained separately on each aphid species. The rearing jars were provided by a crumpled paper to support as an oviposition site. The eggs laid were collected daily, transferred to clean Petri dishes and allowed to hatch. The culture was maintained at the laboratory conditions of $25 \pm 2{ }^{\circ} \mathrm{C}$ and $65 \pm 5 \% \mathrm{RH}$. Newly emerged larvae of $H$. convergens from the stock were the ones used in the experiments.

\section{Life table parameters}

To study the pre-imaginal development and survival, groups of about 40 eggs of $H$. convergens were obtained from the adults reared on the 2 different aphid species that placed separately in clean Petri plates. The egg incubation period was recorded at $12 \mathrm{~h}$ intervals. On hatching, larvae were fed on A. gossypii and L. erysimi separately. The experimental unit consisted of falcon centrifuge polypropylene tube $(12 \mathrm{~cm}$ in length and 3 $\mathrm{cm}$ in diameter) containing 1 predator larva and aphid diet that was provided daily. First and second larval instars of $H$. convergens were provided by 101 st and 2nd nymphal instars of each aphid species and later larval instars were provided by 20 3rd and 4th instars of each host aphid. Development of larval and pupal durations was recorded at $12 \mathrm{~h}$ intervals. The adults of $H$. convergens were selected from the corresponding experiment with the immature stages. Additional culture was also maintained to harvest a sufficient number of adult females when required. The adult pairs of $H$. convergens were isolated, and kept in transparent plastic jars containing 1-2 branches of each host plant; dipped in plastic vials containing water. Similarly, the adult pairs were fed daily on L. erysimi and A. gossypii. The laid eggs were separated daily for each couple. Data were recorded daily to determine the fecundity rate and adult longevity. The fecundity rate, developmental duration, adult preovipositional period (APOP), and total APOP based on an age-stage two-sex life table (Chi 1988) was determined by using the computer program TWOSEXMSChart (Chi 2016). Age-specific survival rates and life expectancy were calculated according to Chi and Liu (1985) and Chi and Su (2006), respectively.

\section{Data analysis}

The developmental duration and population parameters were calculated using TWOSEX-MSChart program. The bootstrapping technique with 100,000 replications was used to minimize the variation in the

Table 1 Developmental period (mean \pm SE) of Hippodamia convergens fed on two aphid species

\begin{tabular}{lllll}
\hline Life stages & $\mathrm{n}$ & A. gossypii & $n$ & L. erysimi \\
\hline Egg incubation & 40 & $3.15 \pm 0.12 \mathrm{a}$ & 40 & $2.45 \pm 0.08 \mathrm{~b}$ \\
L1 & 38 & $4.03 \pm 0.12 \mathrm{a}$ & 40 & $2.55 \pm 0.08 \mathrm{~b}$ \\
L2 & 32 & $5.10 \pm 0.14 \mathrm{a}$ & 36 & $2.61 \pm 0.09 \mathrm{~b}$ \\
L3 & 24 & $5.50 \pm 0.23 \mathrm{a}$ & 34 & $2.32 \pm 0.07 \mathrm{~b}$ \\
L4 & 23 & $6.82 \pm 0.19 \mathrm{a}$ & 32 & $3.81 \pm 0.13 \mathrm{~b}$ \\
Pupa & 23 & $6.82 \pm 0.19 \mathrm{a}$ & 32 & $4.47 \pm 0.10 \mathrm{~b}$ \\
Adult longevity & 22 & $30.6 \pm 0.56 \mathrm{~b}$ & 32 & $36.4 \pm 0.50 \mathrm{a}$ \\
\hline
\end{tabular}

SE was estimated by Bootstrapping (100,000 replications), L1-L4 indicate the larval instar, means sharing similar letters in each row are not significantly different at $P>0.05, n=$ numbers of individual $H$. convergens that completed a stage 
results for calculating the mean and standard error of the population (Efron and Tibshirani 1993). Using raw data, the stage mean, age-stage-specific survival rate $\left(S_{\mathrm{xj}}\right)$, age-stage reproductive value $\left(V_{\mathrm{xj}}\right)$, agestage-specific fecundity $\left(f_{\mathrm{xj}}\right)$, age-stage life expectancy $\left(E_{\mathrm{xj}}\right)$, age-specific survival rate $\left(l_{\mathrm{x}}\right)$, age-specific fecundity $\left(m_{\mathrm{x}}\right)$, age-specific net maternity $\left(l_{\mathrm{x}} m_{\mathrm{x}}\right)$, and life table parameters $\left(R_{\mathrm{o}}\right.$, net reproductive rate; $r$, intrinsic rate of increase; $\lambda$, finite rate of increase; and $T$, mean generation time) were calculated. The significant difference between means was estimated using quick paired bootstrapping (paired 1 by 1 ) function in TWOSEX-MSChart program (Chi 2018).

The age-specific survival rate $\left(l \mathrm{x}, m \mathrm{x}\right.$, and $\left.R_{\mathrm{o}}\right)$ was calculated as

$$
\begin{aligned}
& 1_{x}=\sum_{j=1}^{k} S_{x j} \\
& m_{x}=\frac{\sum_{j=1}^{k} S_{x j} f_{x j}}{\sum_{j=1}^{k} S_{x j}}
\end{aligned}
$$

Table 2 Comparison of reproductive and life table parameters (mean $\pm \mathrm{SE}$ ) of Hippodamia convergens fed on two aphid

\begin{tabular}{|c|c|c|}
\hline Parameters & A. gossypii & L. erysimi \\
\hline APOP & $4.286 \pm 0.569 a$ & $02.60 \pm 0.150 b$ \\
\hline TPOP & $35.78 \pm 1.094 a$ & $20.80 \pm 0.415 b$ \\
\hline Oviposition period & $15.90 \pm 0.912 b$ & $20.10 \pm 0.766 a$ \\
\hline Fecundity & $251.0 \pm 13.27 b$ & $319.7 \pm 13.32 \mathrm{a}$ \\
\hline Ro (offspring individual ${ }^{-1}$ ) & $87.85 \pm 19.45 b$ & $159.85 \pm 25.86 a$ \\
\hline$T$ (days) & $45.10 \pm 0.858 a$ & $30.49 \pm 0.442 b$ \\
\hline$r\left(\right.$ days $\left.^{-1}\right)$ & $0.099 \pm 0.005 b$ & $0.166 \pm 0.006 a$ \\
\hline$\lambda\left(\right.$ days $\left.^{-1}\right)$ & $1.104 \pm 0.002 b$ & $1.181 \pm 0.007 a$ \\
\hline
\end{tabular}
species

SE was estimated by bootstrapping $(100,000)$. Whereas APOP, TPOP, $T, r, \lambda$, and Ro represents adult pre-oviposition period, total pre-oviposition period, mean generation time, intrinsic rate of increase, and finite rate of increase, net reproductive rate respectively. Means sharing similar letters in each row are not significantly different at $P>0.05$

$$
R_{o}=\sum_{x=0}^{\infty} l_{x} m_{x}
$$

Where $k$ denotes the number of stages, $x=$ age in days, $j$ = stage, $R_{\mathrm{o}}$ (net reproductive rate) is the average number of offspring per female during its whole life cycle. It was calculated by the following equation:

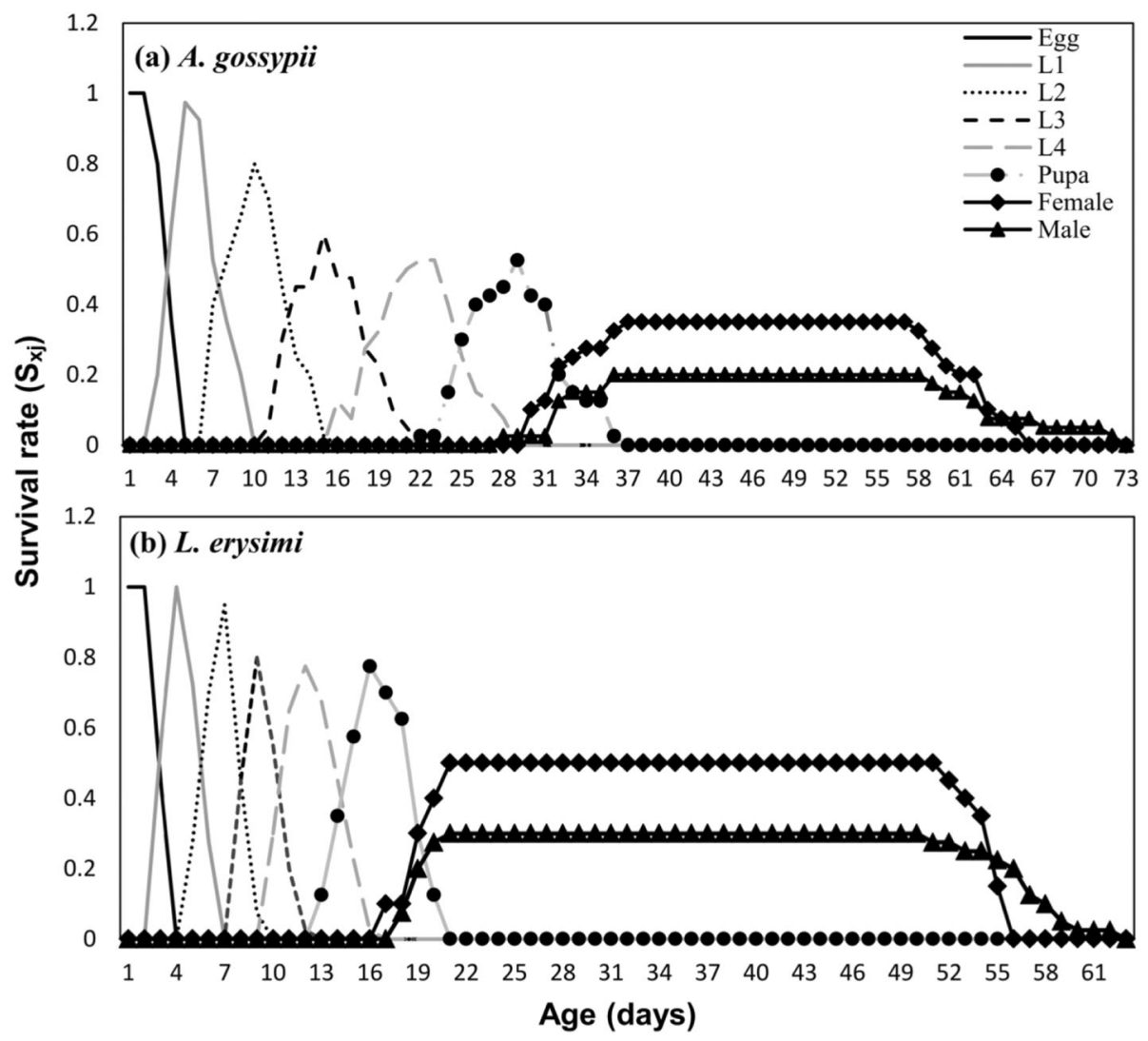

Fig. 1 Age-stage-specific survival rate $\left(S_{x j}\right)$ of Hippodamia convergens fed on two aphid species 
The intrinsic rate of increase $(r)$ (Goodman 1982), finite rate of increase $(\lambda)$, and mean generation time $(T)$ was calculated as

$$
\begin{gathered}
\sum_{x=0}^{\infty} e^{-r(x+1)} l_{x} m_{x}=1 \\
\lambda=e^{r} \\
T=\ln R o / r
\end{gathered}
$$

The life expectancy $\left(E_{\mathrm{xj}}\right)$ was referred as the expected life of an individual of age $x$ and stage $j$ was calculated by the equation suggested by $\mathrm{Chi}$ and $\mathrm{Su}$ (2006):

$$
\mathrm{E}_{x j}=\sum_{i=x}^{\infty} \cdot \sum_{y=j}^{\beta} \mathrm{s}^{\prime}{ }_{i y}
$$

Where $\dot{s}_{\text {iy }}$ was the probability that individuals of age $x$ and stage $j$ will survive to age $i$ and stage $y$, and was calculated by assuming $s=1$.

The reproductive value $\left(V_{\mathrm{xj}}\right)$ was calculated by the equation suggested by Tuan et al. (2014):

$$
V_{x j}=\frac{e^{r(x+1)}}{S_{x j}} \sum_{i=x}^{\infty} e^{-r(i+1)} \sum_{y=j}^{\beta} \mathbf{s}_{i y}^{\prime} f_{i y}
$$

\section{Results and discussion}

The developmental period of each stage of $H$. convergens feeding on two aphid species was presented in Table 1. The egg incubation period was shorter (2.45 days) in the females fed on L. erysimi than those fed on A. gossypii (3.15 days). The findings are also in similar to Abbas et al. (2020) who reported that incubation period of the coccinellid, Menochilus sexmaculatus fluctuated feeding on different aphid species. Similarly, the developmental period of all four larval instars was shorter when they fed on $L$. erysimi than on A. gossypii. The pupal period was 4.47 days when the larvae were fed on L. erysimi, which was shorter than those fed on A. gossypii (6.82 days). Adults lived 5.8 days more when fed on L. erysimi than on A. gossypii host. Adult pre-ovipositional (APOP) and total pre-ovipositional (TPOP) periods were shorter (2.60 and 20.80 days, respectively), when adults fed on $L$. erysimi, while they were 4.86 days of APOP and 35.78 days of TPOP in case of fed on A. gossypii (Table 2).

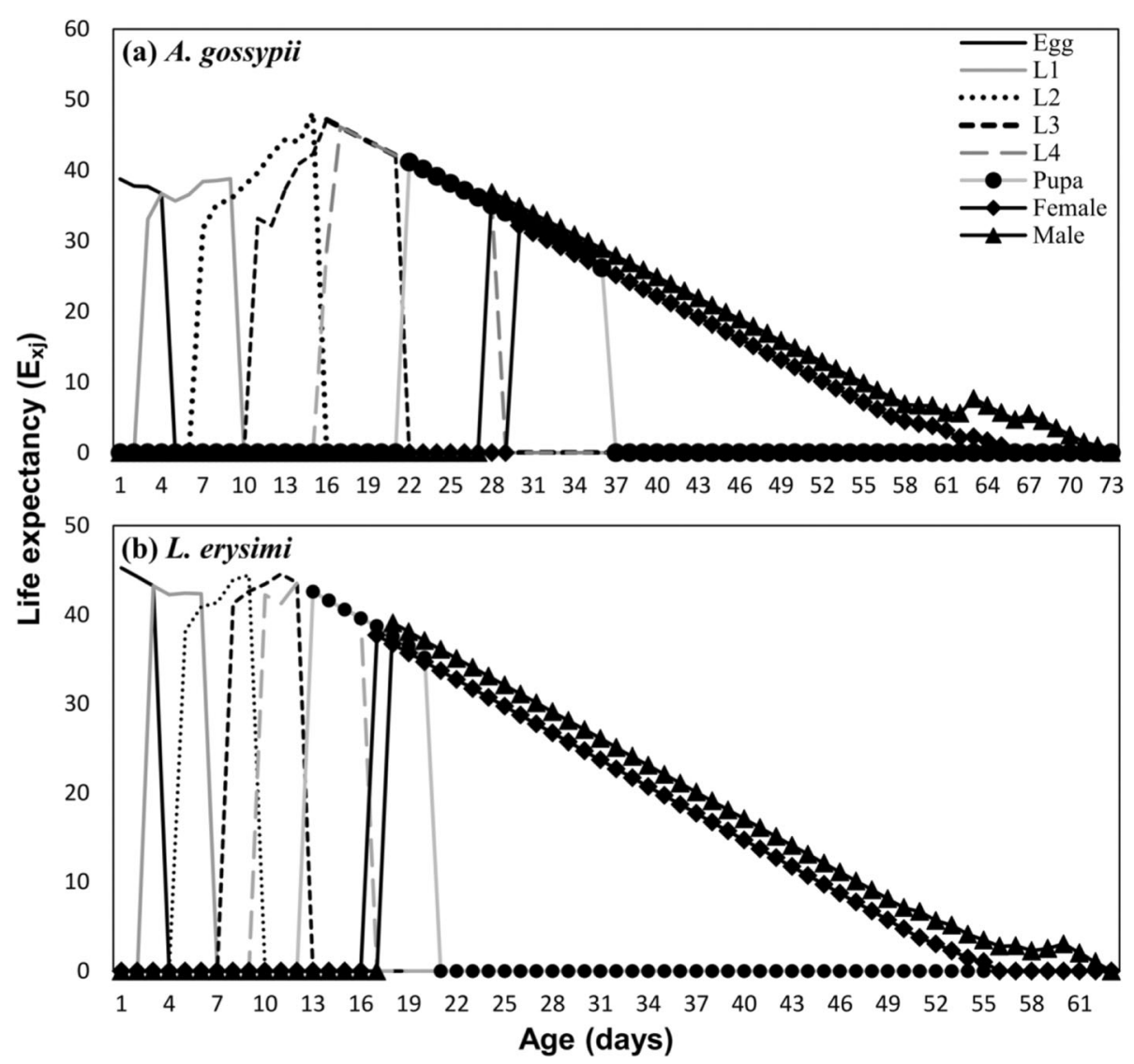

Fig. 2 Age-stage-specific life expectancy $\left(E_{\mathrm{x} j}\right)$ of Hippodamia convergens fed on two aphid species 
These findings are contradicted with the studies conducted on seven spotted ladybird, Coccinella septempunctata $\mathrm{L}$. that the TPOP beetles was maximum on $L$. erysimi (Ali and Rizvi 2010; Farooq et al. 2018). However, these variations in the results could be due to difference in biotic and abiotic factors (Kontodimas and Stathas 2005). The ovipositional period was also longer (20.1 days), when the female fed on L. erysimi, and 15.9 days in female fed on A. gossypii. However, Farooq et al. (2018) reported maximum ovipositional period of C. septempunctata on L. erysimi. Net reproductive rate $\left(R_{\mathrm{o}}\right)$ of $H$. convergens varied from 87.85 offspring on A. gossypii to 159.8 offspring on L. erysimi. Mean generation time (T) varied from 45.1 days on $A$. gossypii to 30.49 days on L. erysimi. Similarly, both of the intrinsic rate of increase $(r)$ and finite rate of increase $(\lambda)$ were higher $(0.166$ and 1.181 days $^{-1}$, respectively), when they fed on $L$. erysimi compared to those fed on A. gosyypii (0.099 days ${ }^{-1}$ and 1.104 days $^{-1}$, respectively) (Table 2 ).

The performance of $H$. convergens was assessed by the interactive effects of two aphid species. A. gossypii was less palatable to $H$. convergens than $L$. erysimi. Prey quality may influence the longevity, fecundity, and survival of coccinellid (Ghafouri Moghaddam et al. 2016). Majerus and Kearns (1989) reported that quality of prey has a greater impact on the egg incubation and duration of larval instars of the seven spotted ladybird beetle, Coccinella septempunctata $\mathrm{L}$. The development of coccinellids may be affected by the type of prey; food with low-quality delays the development, whereas high-quality or nutritional food promotes the development (Snyder et al. 2000). Obtained results showed that adult longevity of $H$. convergens was higher when those fed on L. erysimi as compared to A. gossypii. The female longevity was higher than male feeding on both aphid species and the results are comparable with the findings of Sarwar and Saqib (2010). The findings are also in line with Ali and Rizvi (2007), who reported that the duration of coccinellid adult was longer on L. erysimi than on Macrosiphum rosae (Linnaeus).

Similarly, the female fecundity is also dependent on the quality of host aphid species. In the present study, 319.7 eggs were laid when $H$. convergens was fed on $L$. erysimi and 251.0 eggs for those fed on A. gossypii. The prey density may also influence the fecundity rate of coccinellid females. Twenty aphids were provided to each $H$. convergens adult pair; however, Dehkordi et al. (2013) reported that the fecundity rate increased by increasing the prey density.

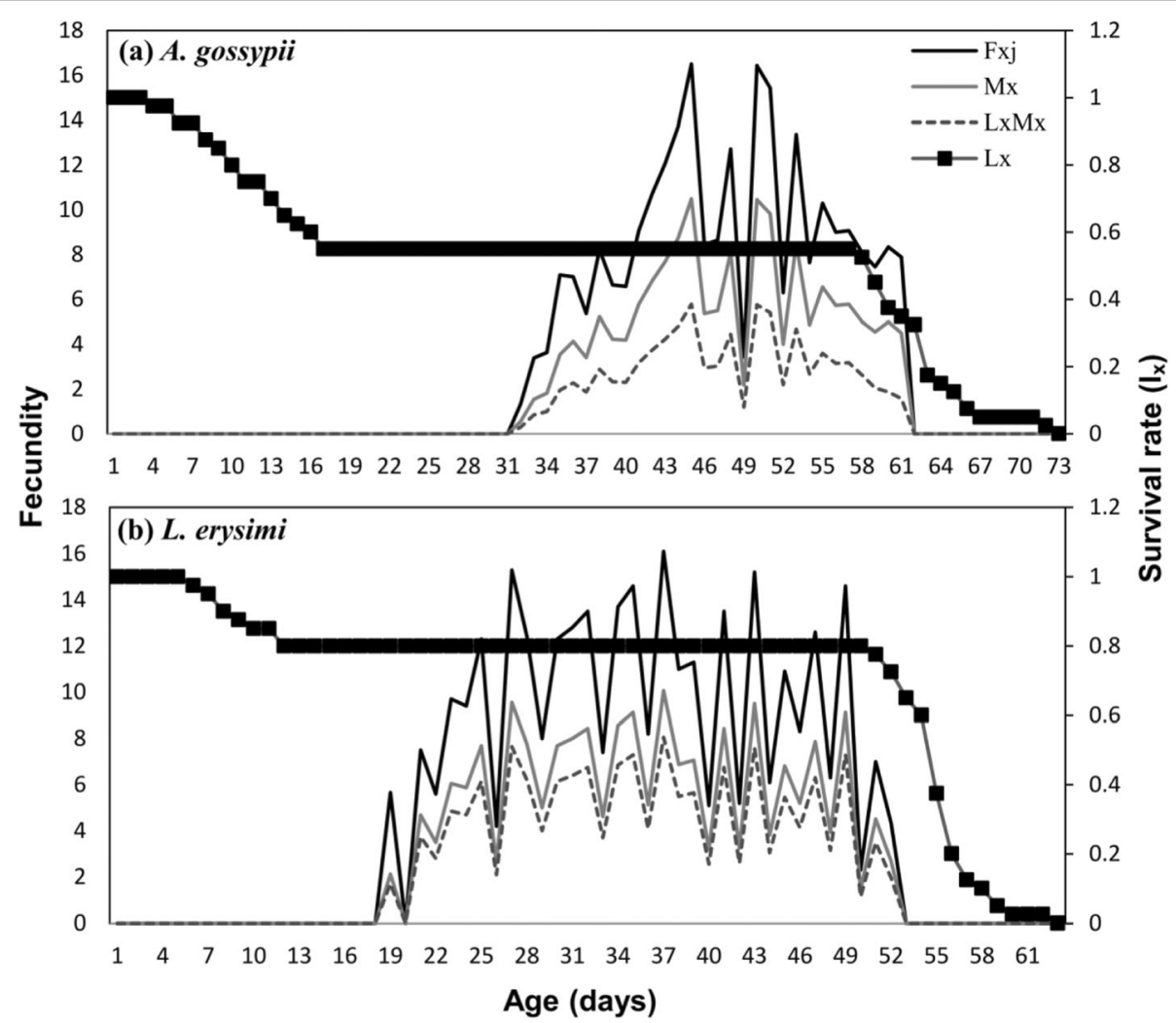

Fig. 3 Age-specific survival rate $(\mid \mathrm{x})$, age-stage-specific fecundity $\left(f_{x}\right)$, age-specific fecundity $(\mathrm{mx})$, and age-specific maternity $\left(I_{x} m_{x}\right)$ of Hippodamia convergens fed on two aphid species 
The net reproductive rate $\left(R_{\mathrm{o}}\right)$, intrinsic rate of increase $(r)$, finite rate of increase $(\lambda)$, and the survival rate of $H$. convergens were higher in case of $L$. erysimi than those fed on A. gossypii. The intrinsic rate of increase $(r)$ is the most valuable parameter in the life table to compare the potential of population growth (Southwood 1966). Predators with short pre-ovipositional periods are expected to have a high $r$ value (Lewontin 1965). In the present study, the $r$ value for $H$. convergens was 0.099 on A. gossypii and 0.166 on L. erysimi. The $r$ value for coccinellid beetle feeding on A. gossypii was reported as 0.178 by Kontodimas and Stathas (2005) and 0.187 by Dehkordi et al. (2013).

The age-stage-specific survival rate $\left(S_{\mathrm{xj}}\right)$ curves show that the survival rate of $H$. convergens was higher when fed on L. erysimi (Fig. 1). The findings are similar to the study of (Ali and Rizvi 2007) C. septempunctata in which maximum developmental rate was recorded on $L$. erysimi than other aphid species. Thus, the quality of prey affects the developmental rate of both immature and adult stages. The age-stage-specific life expectancy curves $\left(E_{\mathrm{xj}}\right)$ was illustrated in Fig. 2. Newly hatched eggs of $H$. convergens were predicted to live for $45.2 \mathrm{~d}$ on $L$. erysimi, and 38.78 days on A. gossypii. The life expectancy $\left(E_{\mathrm{xj}}\right)$ of an adult male was found longer than for adult females in the case of both host aphid species. The life expectancies of 37.7 for females and 39.08 for males were recorded when fed on L. erysimi after 16 and 17 days, respectively and were higher than values recorded for A. gossypii (32.14 for female at 29 days and 36.8 for the male at 27 days) (Fig. 2). The $E_{\mathrm{xj}}$ is that an adult is supposed to live at age $x$ and stage $j$. The $E_{\mathrm{xj}}$ gradually reduced with the age if there was no stress (Atlihan and Chi 2008; Bailey et al. 2011). The $E_{x j}$ of same age individuals can be changed, due to difference in the life stages of individuals (Chi and Su 2006). The $f_{\mathrm{xj}}$ curve showed that $H$. convergens had a higher fecundity rate on A. gossypii than L. erysimi species; however, the difference was little. The highest age-stage-specific female fecundity curve $\left(f_{\mathrm{xj}}\right)$ showed that 16.5 eggs on the 45 th and 16.4 on the 51st days were produced, when fed on A. gossypii. While 15.3 eggs on the 27th, 16.1 eggs on 37 th and 15.2 eggs on 45th days were produced, when female fed on $L$. erysimi. Age-specific survival rate $\left(l_{\mathrm{x}}\right)$ of $H$. convergens was higher on $L$. erysimi than A. gossypii host aphid species (Fig. 3).

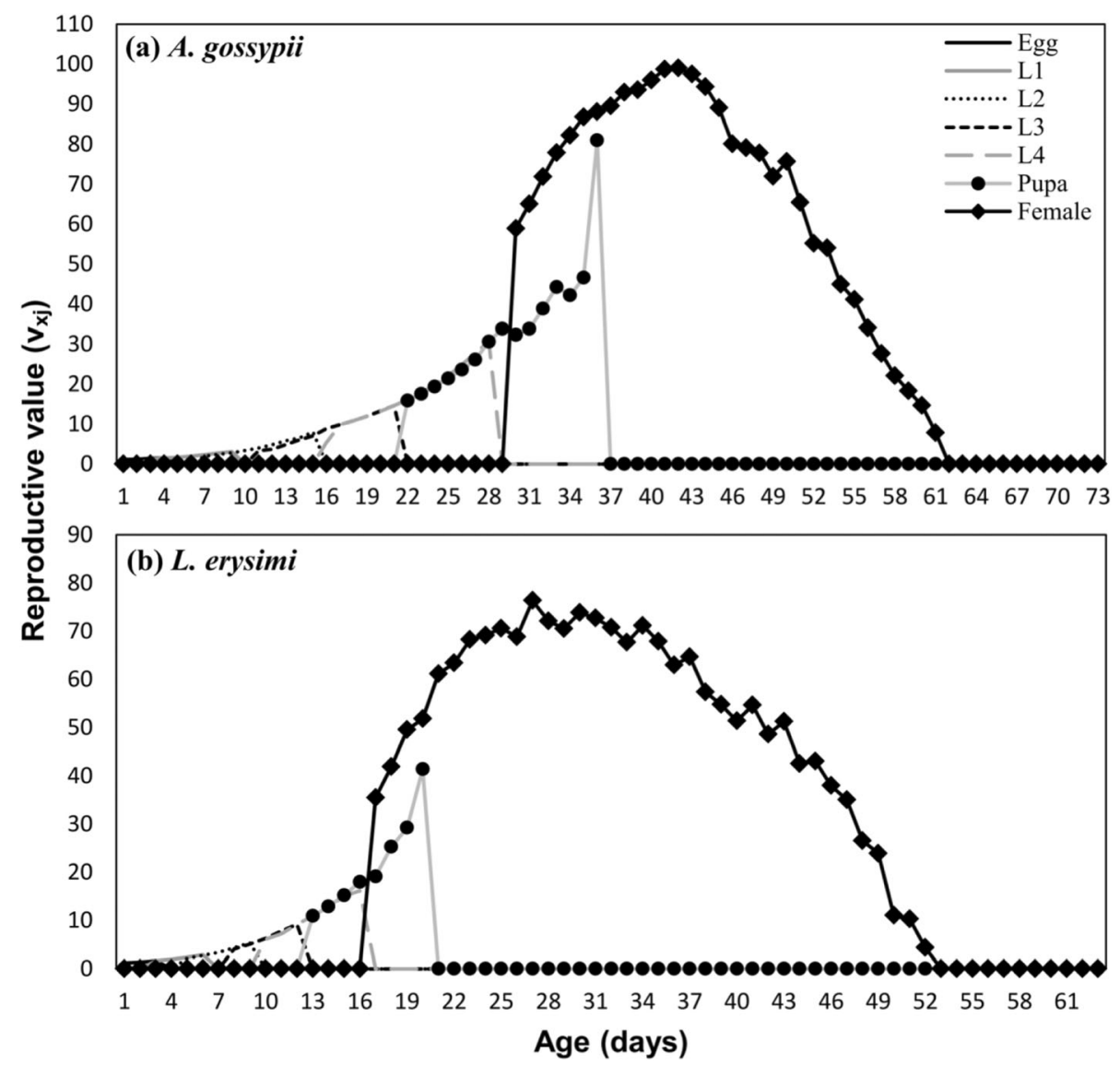

Fig. 4 Age-stage-specific reproductive rate $\left(V_{x j}\right)$ of Hippodamia convergens fed on two aphid species 
Age-stage-specific reproductive rates $\left(V_{\mathrm{xj}}\right)$ representing the contribution of an individual of age $x$ and stage $j$ to the future population is given in Fig. 4. The contribution of an adult female of $H$. convergens to the future population was higher relative to other life stages. $V_{\mathrm{xj}}$ value of adult females was recorded 76.3 after 27 days fed on L. erysimi and 98.2 after 42 days on A. gossypii species (Fig. 4). However, all the biological parameters may be influenced by various biotic and abiotic factors, including the host plant, nature of the prey species, and the environmental conditions. The high-quality food decreases the length of pre-ovipositional period (Omkar and Srivastava, 2003) and consumption of highly nutritive food support early ovariole maturation and sustained a longer oviposition period (Honek 1980).

\section{Conclusion}

Conclusively, aphid species influenced the demographic parameters of $H$. convergens. L. erysimi was a suitable prey than $A$. gossypii where $H$. convergens had good development and demographic parameters. The present findings could be useful for mass rearing of $H$. convergens predator.

\section{Abbreviations}

$S_{x j}$ : Age-stage-specific survival rate; $V_{x j}$ : age-stage reproductive value; $f_{x j}$ : agestage-specific fecundity; $E_{\mathrm{x} j}$ : Age-stage life expectancy; $l_{x}$ : Age-specific survival rate; $m_{x}$ : Age-specific fecundity; $I_{x} m_{x}$ : Age-specific net maternity; $R_{0}$ : Net reproductive rate; $r$ : Intrinsic rate of increase; $\lambda$ : Finite rate of increase; $T$ : Mean generation time

\section{Acknowledgements}

The authors are thankful to the Department of Plant Pathology, University of Sargodha, for providing facilities for the experiment.

\section{Authors' contributions}

M Arshad MI Ullah planned and designed the project and experimental layout. MI Khan, U Shahid, M Abrar, and MM Niaz performed the experiment. M Tahir and M Rlzwan performed the statistical analysis. The manuscript was prepared by M Arshad and reviewed by MI Ullah and M Rizwan. All authors read and approved the final manuscript.

\section{Funding}

There is no funding source to be declared for this study.

\section{Availability of data and materials}

Data will not be shared

\section{Ethics approval and consent to participate}

Not applicable

\section{Consent for publication \\ Not applicable}

\section{Competing interests}

The authors declare that they have no competing interests

\section{Author details}

${ }^{1}$ Department of Entomology, University of Sargodha, Sargodha 40100, Pakistan. ${ }^{2}$ China-Pakistan Joint Research Centre for Citrus Disease and Insect Pest Management, University of Sargodha, Sargodha 40100, Pakistan. ${ }^{3}$ Department of Entomology, University College of Agriculture and Environmental Sciences, Islamia University Bahawalpur, Bahawalpur 63100, Pakistan. ${ }^{4}$ Rice Research Institute, Kala Shah Kaku, Lahore 39020, Pakistan.
Received: 30 March 2020 Accepted: 3 June 2020

Published online: 23 June 2020

\section{References}

Abbas K, Zaib MS, Zakria M, Hani UE, Zaka SM, Ain NU (2020) Age-stage, two-sex life table of the Menochilus sexmaculatus (Coccinellidae: Coleoptera) feeding on different aphid species. bioRxiv https://doi.org/10.1101/2020.01.15.907576

Ali A, Rizvi PQ (2007) Development and predatory performance of Coccinella septempunctata L. (Coleoptera: Coccinellidae) on different aphid species. J Biol Sci 7:1478-1483

Ali A, Rizvi PQ (2010) Age and stage specific life table of Coccinella septempunctata (Coleoptera: Coccinellidae) at varying temperature. World J Agri Sci 6(3):268-273

Amin M, Mahmood K, Bodlah I (2017) Aphids (Homoptera: Aphididae) infesting medicinal and aromatic plants in the Poonch Division of Azad Jammu and Kashmir, Pakistan. J Anim Plant Sci 27(4):1377-1385

Aslam M, Razaq M, Akhter W, Faheem M, Ahmad F (2005) Effect of sowing date of wheat on aphid (Schizaphis gramium Rondani) population. Pak Entomol 27:79-82

Atlihan R, Chi H (2008) Temperature-dependent development and demography of Scymnus subvillosus (Coleoptera: Coccinellidae) reared on Hyalopterus pruni (Homoptera: Aphididae). J Econ Entomol 101(2):325-333

Bailey R, Chang NT, Lai PY (2011) Two-sex life table and predation rate of Cybocephalus flavocapitis Smith (Coleoptera: Cybocephalidae) reared on Aulacaspis yasumatsui Takagi (Hemiptera: Diaspididae), in Taiwan. J Asia Pac Entomol 14(4):433-439

Berkvens N, Bonte J, Berkvens D, Tirry L, De Clercq P (2008) Influence of diet and photoperiod on development and reproduction of European populations of Harmonia axyridis (Pallas) (Coleoptera: Coccinellidae). BioControl 53:211-221

Chi H (1988) Life-table analysis incorporating both sexes and variable development rates among individuals. Environ Entomol 17:26-34

Chi H (2016) TWO SEX-MSChart: Computer program for age stage, two-sex life table analysis. http://140.120.197.173/ecology/.

Chi H (2018) TWOSEX-MSChart: a computer program for the age-stage, two-sex life table analysis. National Chung Hsing University, Taichung, Taiwan, (http://140.120.197.173/Ecology/Download/Twosex-MSChart.zip) (accessed 23 Mar 2020).

Chi H, Liu H (1985) Two new methods for the study of insect population ecology. Bull Inst Zool Acad Sin 24:225-240

Chi H, Su HY (2006) Age-stage, two-sex life tables of Aphidius gifuensis (Ashmead) (Hymenoptera: Braconidae) and its host Myzus persicae (Sulzer) (Homoptera: Aphididae) with mathematical proof of the relationship between female fecundity and the net reproductive rate. Environ Entomol 35:10-21

De Clercq P, Bonte M, Van Speybroeck K, Bolckmans K, Deforce K (2005) Development and reproduction of Adalia bipunctata (Coleoptera: Coccinellidae) on eggs of Ephestia kuehniella (Lepidoptera: Phycitidae) and pollen. Pest Manag Sci 61(11):1129-1132

Dehkordi SD, Sahragard A, Hajizadeh J (2013) The effect of prey density on life table parameters of Hippodamia variegata (Coleoptera: Coccinellidae) fed on Aphis gossypii (Hemiptera: Aphididae) under laboratory conditions. ISRN Entomol 2013:1-7

Dixon AFG (2000) Insect predator-prey dynamics: Ladybird beetles and biological control. Cambridge University Press, Cambridge

Efron B, Tibshirani RJ (1993) An introduction to the bootstrap. J Am Stat Assoc $89: 436$

Farooq M, Shakeel M, Iftikhar A, Shahid MR, Zhu X (2018) Age-stage, two-sex life tables of the lady beetle (Coleoptera: Coccinellidae) feeding on different aphid species. J Econ Entomol 111(2):575-585

Ghafouri Moghaddam M, Golizadeh A, Hassanpour M, Rafiee-Dastjerdi H, Razmjou J (2016) Demographic traits of Hippodamia variegata (Goeze)(Coleoptera: Coccinellidae) fed on Sitobion avenae Fabricius (Hemiptera: Aphididae). J Crop Protec 5:431-445

Goodman D (1982) Optimal life histories, optimal notation, and the value of reproductive value. Am Nat 119(6):803-823.

Hodek I, Van Emden HF, Honek A (2012) Ecology of Coccinellidae. WileyBlackwell, Dordrecht

Honek A (1980) Population density of aphid at the time of settling and ovariole maturation in Coccinella septempunctata (Coleoptera: Coccinellidae). Entomophaga 23:213-216

Jervis MA, Copland MJW, Harvey JA (2005) The life cycle. In: Jervis MA (ed) Insects as Natural Enemies: A Practical Perspective. Springer, pp 73-165 
Jessie WP, Giles KL, Rebek EJ, Payton ME, Jessie CN, McCornack BP (2015) Preference and performance of Hippodamia convergens (Coleoptera: Coccinellidae) and Chrysoperla carnea (Neuroptera: Chrysopidae) on Brevicoryne brassicae, Lipaphis erysimi, and Myzus persicae (Hemiptera: Aphididae) from winter-adapted canola. Environ Entomol 44:880-889

Khan AA, Zaki FA, Khan ZH, Mir RA (2009) Biodiversity of predacious ladybird beetles (Coleoptera: Coccinellidae) in Kashmir. J Biol Control 23:43-47

Kontodimas DC, Stathas GJ (2005) Phenology fecundity and life table parameters of the predator Hippodamia variegata reared on Dyaphis crataegi. Biocontrol 50(2):223-233

Lewontin RC (1965) Selection for colonizing ability. In: The genetics of colonizing species: Proceedings of the First International Union of Biological Sciences Symposia on General Biol, 1965. Academic Press, New York, pp 77-94

Lundgren JG (2009) Nutritional aspects of non-prey foods in the life histories of predaceous Coccinellidae. Biol Control 51:294-305

Lundgren JG, Wiedenmann RN (2004) Nutritional suitability of corn pollen for the predator Coleomegilla maculate (Coleoptera: Coccinellidae). J Insect Physiol 150:567-575

Majerus M, Kearns P (1989) Ladybirds, Naturalist Handbook, vol 10. The Richmond Publishing Co. Ltd, Dorset

Omkar, Mishra G (2005) Preference - performance of a generalist predatory ladybird: a laboratory study. Biol Control 34:187-195

Omkar, Srivastra S (2003) Influence of six aphid prey species on development and reproduction of ladybird beetle, Coccinella septempunctata. Biol Control 48:379-393

Pervez A, Awasthi P, Bozdoğan H (2018) Demographic parameters of the predaceous ladybird, Hippodamia variegata (Goeze), on the aphid species, Aphis craccivora (Koch), reared on four host plants. Egypt J Biol Pest Co 28(1):91

Sarwar M, Saqib SM (2010) Rearing of predatory seven spotted lady-bird beetle Coccinella septempunctata L.(Coleoptera: Coccinellidae) on natural and artificial diets under laboratory conditions. Pak J Zool 42:47-51

Snyder WE, Joseph SB, Preziosi R, Moore AJ (2000) Nutritional benefits of cannibalism for the lady beetle Harmonia axyridis (Coleoptera: Coccinellidae) when prey quality is poor. Environ Entomol 29:1173-1179

Southwood R (1966) Ecological Methods: with particular reference to the study of insect populations/T.R.E. southwood. Methuen, London

Sutherland AM, Parrella MP (2009) Mycophagy in Coccinellidae: review and synthesis. Biol Control 51:284-293

Tuan SJ, Lee CC, Chi H (2014) Population and damage projection of Spodoptera litura (F.) on peanuts (Arachis hypogaea L.) under different conditions using the age-stage, two-sex life table. Pest Mgt Sci 70:805-813

Yu JZ, Chi H, Chen BH (2013) Comparison of the life tables and predation rates of Harmonia dimidiata (F.)(Coleoptera: Coccinellidae) fed on Aphis gossypii Glover (Hemiptera: Aphididae) at different temperatures. Biol Control 64(1):1-9

\section{Publisher's Note}

Springer Nature remains neutral with regard to jurisdictional claims in published maps and institutional affiliations.

\section{Submit your manuscript to a SpringerOpen ${ }^{\circ}$ journal and benefit from:}

- Convenient online submission

- Rigorous peer review

- Open access: articles freely available online

- High visibility within the field

- Retaining the copyright to your article

Submit your next manuscript at $\boldsymbol{\nabla}$ springeropen.com 